\title{
Vendor rating for an entrepreneur development programme: a case study using the analytic hierarchy process method
}

\begin{abstract}
With collaborative purchasing programmes where one of the aims is to develop suppliers, vendor rating is important not only in supplier selection and in deciding how to allocate business but also to determine where scarce development effort is best applied. This paper describes a case study into vendor rating for a government sponsored Entrepreneur Development programme in Malaysia. The paper reviews current methods for vendor rating and finds them wanting. It illustrates a new approach based on the use of Saaty's Analytic Hierarchy process method, which was developed to assist in multi-criteria decision problems. The new method overcomes the difficulties associated with the categorical and simple linear weighted average criteria ranking methods. It provides a more systematic way of deriving the weights to be used and for scoring the performance of vendors.
\end{abstract}

Keyword: Vendor rating; Analytic hierarchy process; Multi criteria decision making; Purchasing; Development programmes 